\title{
OXYGEN DIFFUSION THROUGH POLYMER MEMBRANES UNDER NON-STEADY-STATE CONDITIONS
}

\author{
MARIANNE S. EIKELAND ${ }^{1}$, HANS-KRISTIAN ALMOEN GRAVKLEV ${ }^{1}$, HUI HUANG ${ }^{1}$, \\ VIBEKE BREDVOLD KARLSEN ${ }^{1}$, ANNE KATRINE SEM ${ }^{1}$, TOMMY STOKKA ${ }^{1}$, \\ MORTEN AUGESTAD ${ }^{2}$ \& KJELL-ARNE SOLLI ${ }^{1}$ \\ ${ }^{1}$ Norway Department of Process, Energy and Environmental Technology, \\ University of South-Eastern Norway, Norway \\ ${ }^{2}$ Norner AS, Norway
}

\begin{abstract}
Polymers are used as food packaging material to preserve the food and to increase the shelf life. Oxygen accelerates the growth of bacteria and other microorganisms and can reduce the durability of the food. By using polymers as a food packaging material, the decomposition and the amount of food waste can be reduced. It is therefore important to predict the diffusion rate of oxygen through the polymers when a certain type of polymer is used. The main goal of this article is to study the influence of temperature variations on the oxygen diffusion through a polymer material. Laboratory experiments are performed by measuring the concentration of oxygen in nitrogen filled polypropylene boxes under constant temperatures and with temperature variations over time. The experiments show that the oxygen diffusion increases with increasing temperature. An effect of changing the temperature is that the permeation rate in the polymer becomes higher when the polymer has first been exposed to a higher temperature. This is an important observation and has to be taken into account when food is exposed to different temperatures during transport and storage. A mathematical model is formulated to estimate the oxygen concentration in the boxes. The comparison between literature data, the model and the experimental results indicates that, although there is deviation between the data, the tendency of increase in oxygen concentration with time is the same.
\end{abstract}

Keywords: polypropylene, permeability coefficients, $\mathrm{O}_{2}$ diffusion, DBI Dansensor PerMate.

\section{INTRODUCTION}

Polymers are widely used for food packaging, medicine or cosmetics, and the different applications require different polymer qualities. Food packaging is used to protect the food products from damage and influence from the surrounding atmosphere, and thereby extend the shelf life of foods and reduce the amount of food waste. The advantages of using polymers as packaging materials are that polymers have longer durability, lower weight and lower costs compared to alternative materials as glass and metal. The disadvantage of using polymers is that they have high permeability. Permeability is the transfer rate of molecules through a barrier. This means that low molecular weight compounds like gases, water vapour, flavour, aromas etc. can diffuse through the walls of the packaging material. A high transfer of oxygen through the polymer can result in bacterial growth and food degradation and thereby reduction of the shelf life of food. Shelf life can be defined as the time food products can be stored, and still maintaining an acceptable quality or specific functionality [1]. Evaluation of the barrier properties of polymers is crucial for selecting the appropriate polymer material for food or beverage packaging. Diffusion of gases through the polymeric material should be prevented or minimized to maintain product quality and freshness during distribution and storage. The amount of packaging material used is also important in the evaluation of shelf life versus material consumption. Production and handling of the packaging material are other factors that can influence the choice of polymer as packing material [2]-[4]. 
Understanding the effect of the barrier properties of food packaging can contribute to reducing food waste. Oxygen diffusion through a polymer material depends on the temperature. Food is exposed to different temperatures during packaging, transport and storage. Food is often packed at a temperature of $60-100^{\circ} \mathrm{C}$ and then cooled down to $0-4^{\circ} \mathrm{C}$ or even to $-18^{\circ} \mathrm{C}$ for freezing. If the food has to be stored at these low temperatures, the transportation should also take place in the same temperature range. During loading from the transport vehicle to the store, the product may be exposed to temperature variations for a shorter period. The temperature variations are dependent on the surrounding temperature. During the transportation from the store to the customer's residence, the food will again be exposed to temperature variations. Based on these observations, the oxygen diffusion rate through the packing material has to be tested at the different temperatures to evaluate the effect of temperature variations.

\section{MATERIALS AND METHODS}

A membrane is a selective barrier, which is able to separate components based on the differences in size, shape or chemical structure. Membranes have the ability to transport a certain component more readily than other components because of differences in physical and/or chemical properties between the membrane and the permeating components [5]. The mass diffusion through a membrane is due to the driving forces acting on the components in the feed. The driving forces can be differences in pressure, concentration or temperature across the membrane. The efficiency of the diffusion is dependent on the permeability. The permeability is a function of the diffusion constant and the concentration gradient over the membrane. This is expressed by Fick's law:

$$
J=-D \frac{d c_{i}}{d x}
$$

where $J$ is the molar flux, $D$ is the diffusion coefficient and $d C_{i}$ is the driving force expressed as the concentration gradient over the membrane thickness $d x$ for component $i$.

A schematic model for gas transport through a polymer membrane under steady state conditions can be described by the solution diffusion mechanism as shown in Fig. 1. The gas diffuses from the bulk phase with high concentration of component $i$ to the polymer membrane surface (1-2). The gas is then absorbed at the surface of the membrane and diffuses through the membrane material (2-4). Next, the gas desorbs from the membrane and diffuses away from the membrane surface and into the bulk phase with low concentration of component $i(4-5)$.

In the solution-diffusion model, assuming an ideal system, the solubility and the diffusivity are constant. The membrane have a uniform thickness, and the pressure through the membrane thickness is uniform. The solubility coefficient is a thermodynamic parameter, and is a measure of a gas absorbed by the membrane under equilibrium conditions.

Integrating Fick's law will give eqn (2), expressing the partial pressure for a component $i, p_{i 2}$, at the low concentration side after a given time $t$,

$$
p_{i 2}=p_{i 1}-\left(p_{i 1}-p_{i 2,0}\right) \cdot e^{-\frac{P R T A t}{z V}}
$$

where $p_{i 2,0}$ is the partial pressure of component $i$ at the low concentration side at $t=0$. $P$ is the permeability coefficient, $V$ is the volume, $R$ is the gas constant, $T$ is the temperature, $A$ is the surface area, $t$ is time, and $z$ is the thickness of the membrane. 


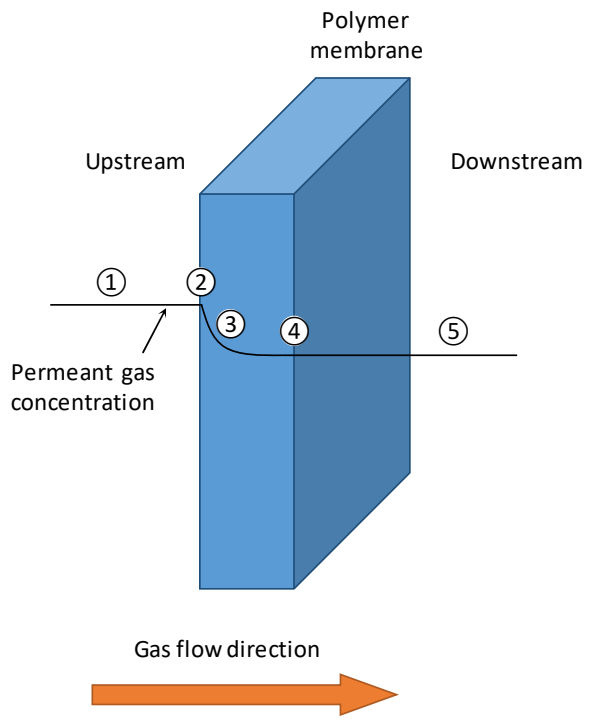

Figure 1: Schematic model of a steady state solution-diffusion mechanism of gas transport through a polymer [5].

The temperature influences the permeation rate through the membrane. In general, an increase in temperature gives an increase in the flux through the membrane. The relationship between the temperature and the permeability can be expressed by the Arrhenius equation [5]

$$
P=P_{0} \cdot e^{-\left(\frac{E p}{R T}\right)},
$$

where $P_{0}$ is a proportionality constant and $E_{p}$ is the activation energy.

Brandrup et al. [6] presented the proportionality constant and the activation energy for a polymer for a given temperature interval. Eqn (4) can be used to estimate permeability coefficients at a certain temperature based on the permeability coefficient, the proportionality constant and the activation energy given at other temperatures

$$
P_{2}=P_{1} \cdot e^{-\left(\frac{E_{p}}{R}\right) \cdot\left(\frac{1}{T_{2}}-\frac{1}{T_{1}}\right)} .
$$

However, eqn (4) is only valid for small variations in temperature and when there are no strong interactions between the gas and the polymer. In addition, the equation is not valid below the glass transition temperature. The permeability will be lower at temperatures below the glass transition temperature and the relation based on the Arrhenius equation is not applicable [5].

The permeability coefficient of a component is determined based on structure, morphology, crystallinity and density of the polymeric materials. In general, the permeability of polymers decreases with increasing density and crystallinity [5], [6].

Plastic boxes were produced from a random copolymer of polypropylene pellets with a density of $0.905 \mathrm{~g} / \mathrm{cm}^{3}$. The wall thickness of the boxes was $0.32 \mathrm{~mm}$ and the total volume was $850 \mathrm{ml}$. The boxes were sealed by welding a film of polypropylene, aluminum and polyethylene on the top of the boxes at $175^{\circ} \mathrm{C}$. After welding, the transition zone between the 
box and the film was glued to avoid leakage in the transition zone. The curing time was 24 hours. The boxes were stored upside-down between measurements to avoid oxygen transport through the film area. The contact area of the polypropylene is $0.04 \mathrm{~m}^{2}$, welding film excluded. Two septa are placed on the film for flushing with nitrogen before the tests, and for oxygen measurements during the tests. Fig. 2 shows an illustration of a plastic box.

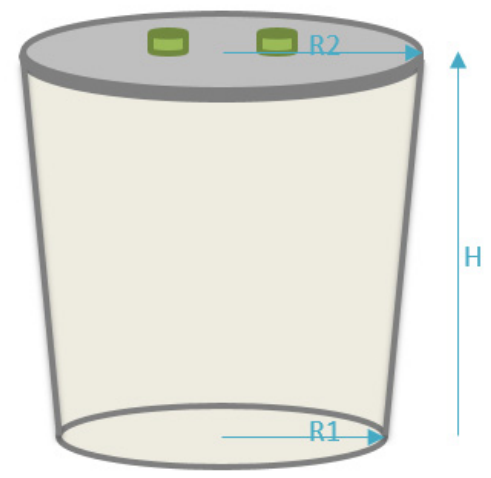

Figure 2: Illustration of the box. $\mathrm{R} 1=4.7 \mathrm{~cm}, \mathrm{R} 2=5.65 \mathrm{~cm}, \mathrm{H}=10.1 \mathrm{~cm}$. Area (top excluded) $=0.040 \mathrm{~m}^{2}$, wall thickness $=0.32 \mathrm{~mm}$.

The oxygen analysis was performed using a DBI Dansensor PerMate to measure the oxygen percentage within the boxes. The oxygen sensor measures the oxygen concentration in the range from 0 to $100 \%$ with an accuracy of $0.005 \%$ to $0.2 \%$ depending on the oxygen level. The boxes were filled with nitrogen and the initial oxygen concentration in the boxes was approximately $1.3 \mathrm{vol} \%$. It was assumed that the pressure inside the box was constant (1 atm) independent of the oxygen diffusion into the box. The concentration of oxygen in the surrounding atmosphere was $20.9 \mathrm{vol} \%$. The oxygen concentration inside the boxes was measured regularly to determine the oxygen transport rate through the polypropylene boxes.

The temperatures used in the experiments are related to typical temperatures used in food industry. The polymer boxes were tested at the freezing temperature of $-18^{\circ} \mathrm{C}$, at the refrigerator temperature of $4^{\circ} \mathrm{C}$, at the room temperature of $23^{\circ} \mathrm{C}$ and at a medium high temperature of $40^{\circ} \mathrm{C}$. All the boxes were tested at these temperatures for a period of 4 weeks. For each series, five boxes were tested in parallel. The boxes were also tested at one temperature for 2 weeks, and then the temperature was changed for the next two weeks.

The permeability coefficients for polypropylene are presented in [6]. The coefficients are given for polypropylene with $50 \%$ crystallinity and a density of $0.907 \mathrm{~g} / \mathrm{cm}^{3}$ at temperatures in the range of $20-70^{\circ} \mathrm{C}$. For this temperature range, the proportionality constant $P_{0}$ is:

$$
P_{0}=278 \cdot 10^{-7} \frac{\mathrm{cm}^{3}\left(273.15 \mathrm{~K} ; 1.013 \cdot 10^{5} \mathrm{~Pa}\right) \cdot \mathrm{cm}}{\mathrm{cm}^{2} \cdot \mathrm{s} \cdot \mathrm{Pa}},
$$

and the activation energy is:

$$
E_{p}=47.7 \mathrm{~kJ} / \mathrm{mol} \text {. }
$$

Based on the literature information, the permeability coefficients are calculated using eqn (3) and presented in Table 1 . Note that the glass transition temperature of polypropylene is in the area $-10^{\circ} \mathrm{C}$ to $-20^{\circ} \mathrm{C}[7]$. 
Table 1: Permeability coefficients of polypropylene from Polymer Handbook [6].

\begin{tabular}{ccc}
\hline $\begin{array}{c}\text { Temperature } \\
\left({ }^{\circ} \mathrm{C}\right)\end{array}$ & $\begin{array}{c}\text { Permeability coefficient } \\
\left(\frac{\mathrm{cm}^{3}\left(273.15 \mathrm{~K} ; 1.013 \cdot 10^{5} \mathrm{~Pa}\right) \cdot \mathrm{mm}}{\mathrm{m}^{2} \cdot \text { day } \mathrm{atm}}\right)\end{array}$ & $\begin{array}{c}\text { Permeability coefficient } \\
\left(\frac{\mathrm{mol}\left(273.15 \mathrm{~K} ; 1.013 \cdot 10^{5} \mathrm{~Pa}\right) \cdot \mathrm{m}}{\mathrm{m}^{2} \cdot \mathrm{day} \cdot \mathrm{Pa}}\right)\end{array}$ \\
\hline$-18^{\circ} \mathrm{C}$ & $4.17($ estimated value $)$ & $1.838 \cdot 10^{-12}$ \\
$4^{\circ} \mathrm{C}$ & $24.88($ estimated value $)$ & $1.095 \cdot 10^{-11}$ \\
$23^{\circ} \mathrm{C}$ & 93.88 & $4.134 \cdot 10^{-11}$ \\
$40^{\circ} \mathrm{C}$ & 268.74 & $1.183 \cdot 10^{-10}$ \\
\hline
\end{tabular}

\section{RESULTS AND DISCUSSION}

When starting the experiments, the oxygen concentration in the boxes was adjusted to approximately $1.3 \mathrm{vol} \%$. The concentration of oxygen increases with time, as the oxygen diffuses through the wall due to the concentration gradient. The results presented in Fig. 3, show that the oxygen concentration within the boxes increases with time. The gradient of the graphs is increasing with increasing temperatures, indicating that the oxygen permeability coefficient increases with temperature.

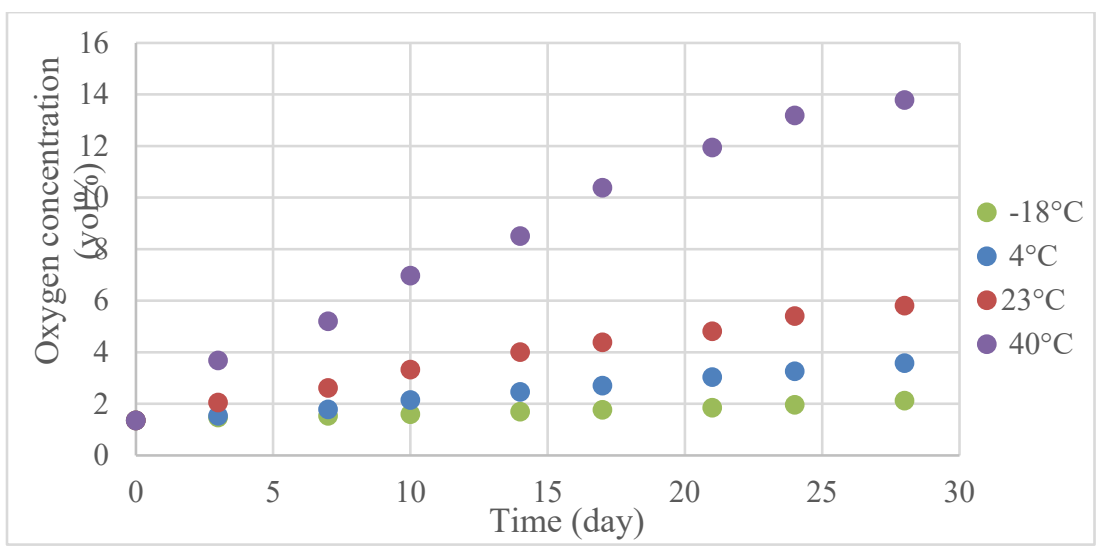

Figure 3: Oxygen concentration in polypropylene boxes as versus time and temperature; the experimental data are average values of 3 to 5 parallels.

The permeability coefficients based on the experimental data are calculated and presented in Table 2. The standard deviation is based on the experimental results. The results presented in Table 2 are of the same order of magnitude as the data given in Table 1, when the standard deviation is taken into account.

In general, as the oxygen concentration in the boxes increases, the concentration gradient decreases and the permeation rate decreases. However, within the time studied, the increase in oxygen concentration is linear for all cases, even though the inclination at $40^{\circ} \mathrm{C}$ seems to decrease at day 28. At this time, the driving forces due to reduced concentration difference of oxygen across the polymer reduce the permeation rate. An estimation of the oxygen concentration over a longer period using eqn (2) and literature data shows that the permeation rate decreases with time for the samples exposed to $40^{\circ} \mathrm{C}$, as shown in Fig. 4. A similar decrease in permeation rate is expected to occur for the other temperatures when the concentration inside the boxes increases toward $20.9 \mathrm{vol} \%$ of oxygen. 
Table 2: Permeability coefficients of polypropylene, measured.

\begin{tabular}{cccc}
\hline $\mathrm{T}\left({ }^{\circ} \mathrm{C}\right)$ & $\begin{array}{c}\text { Permeability coefficient } \\
\left(\frac{\mathrm{cm}^{3}(\mathrm{STP}) \cdot \mathrm{mm}}{\mathrm{m}^{2} \cdot \text { day } \cdot \mathrm{atm}}\right)\end{array}$ & $\begin{array}{c}\text { Permeability coefficient } \\
\left(\frac{\mathrm{mol}(\mathrm{STP}) \cdot \mathrm{m}}{\mathrm{m}^{2} \cdot \text { day } \cdot \mathrm{Pa}}\right)\end{array}$ & $\begin{array}{c}\text { Standard deviation } \\
\left(\frac{\mathrm{cm}^{3}(\mathrm{STP}) \cdot \mathrm{mm}}{\mathrm{m}^{2} \cdot \text { day } \cdot \text { atm }}\right)\end{array}$ \\
\hline$-18^{\circ} \mathrm{C}$ & 9.15 & $4.03 * 10^{-12}$ & 3.78 \\
\hline $4{ }^{\circ} \mathrm{C}$ & 29.19 & $1.29^{*} 10^{-11}$ & 10.35 \\
\hline $23^{\circ} \mathrm{C}$ & 64.13 & $2,61 * 10^{-11}$ & 16.60 \\
\hline $40^{\circ} \mathrm{C}$ & 229.32 & $1.01 * 10^{-10}$ & 32.53 \\
\hline
\end{tabular}

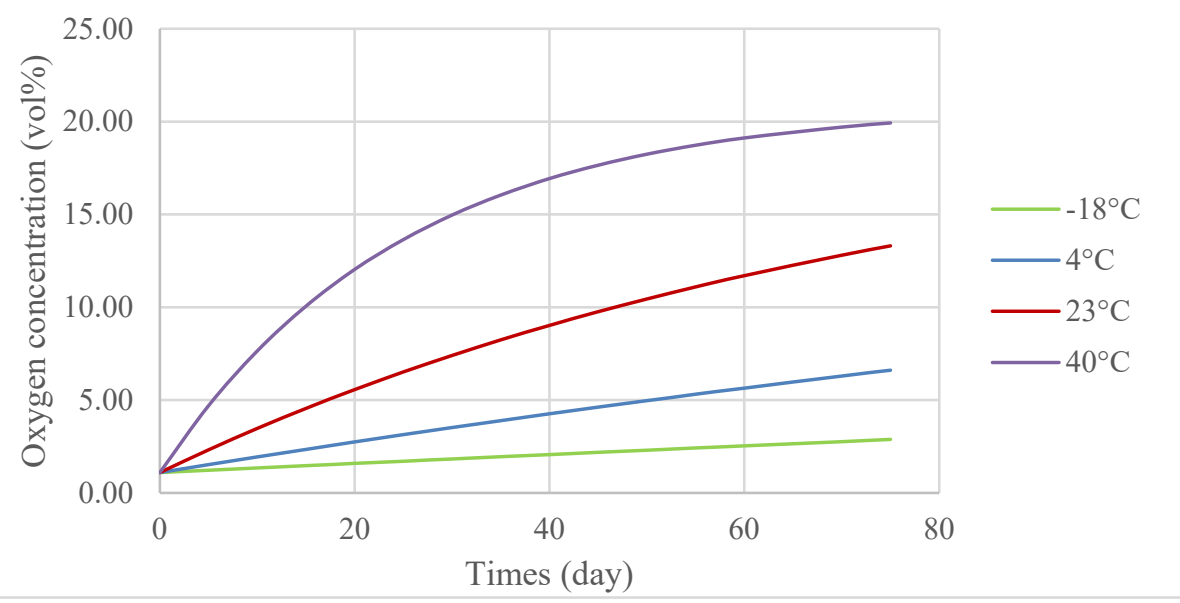

Figure 4: Oxygen concentration in polypropylene as a function of days and temperatures.

In the next experiments, the temperatures were changed after 14 days. The temperature variations together with the results are shown in Fig. 5. The permeability rate of the oxygen through the polymer changes when the temperature is changed. The results in Fig. 5 show that an increase in temperature gives a higher permeation rate, while a decrease in temperature reduces the permeation rate. One effect of changing the temperature may be that the permeation rate increases at the lowest temperature when the polymer is first exposed to a higher temperature. This effect is observed in the case where the temperature is decreased from $23^{\circ} \mathrm{C}$ to $-18^{\circ} \mathrm{C}$, and the permeation rate is higher at $-18^{\circ} \mathrm{C}$ when the material first has been exposed to $23^{\circ} \mathrm{C}$. However, the opposite effect is observed when changing the temperature from $23^{\circ} \mathrm{C}$ to $4^{\circ} \mathrm{C}$ and from $40^{\circ} \mathrm{C}$ to $4^{\circ} \mathrm{C}$. In these cases, the permeation rate is lower at $4^{\circ} \mathrm{C}$ when the material first had been exposed to $23^{\circ} \mathrm{C}$ or $40^{\circ} \mathrm{C}$. For the change in temperatures from $-18^{\circ} \mathrm{C}$ to $23^{\circ} \mathrm{C}$, and from $4^{\circ} \mathrm{C}$ to $40^{\circ} \mathrm{C}$, the permeation rates are reduced for the highest temperatures. However, this effect is not observed when the temperature is changed from $4^{\circ} \mathrm{C}$ to $23^{\circ} \mathrm{C}$, where a minimal increase in the permeation rate is observed when the polymer is first exposed to a low temperature.

Fig. 6 shows a comparison between predictions of the mathematical model presented in eqn (2) based on literature data from Table 1, predictions of the mathematical model based on experimental values from Table 2 and the experimental results. The figure presents the 


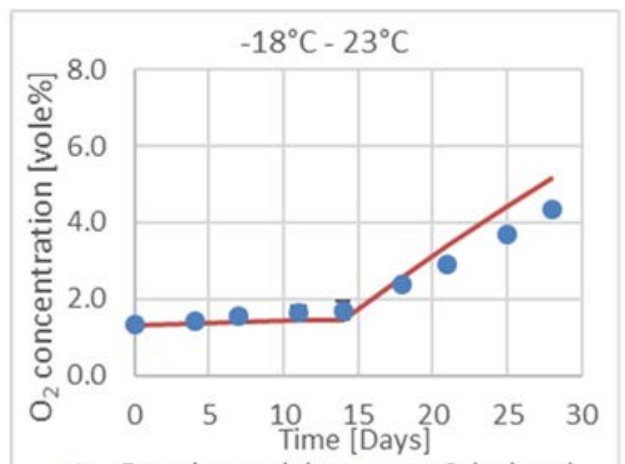

- Experimental data $\longrightarrow$ Calculated
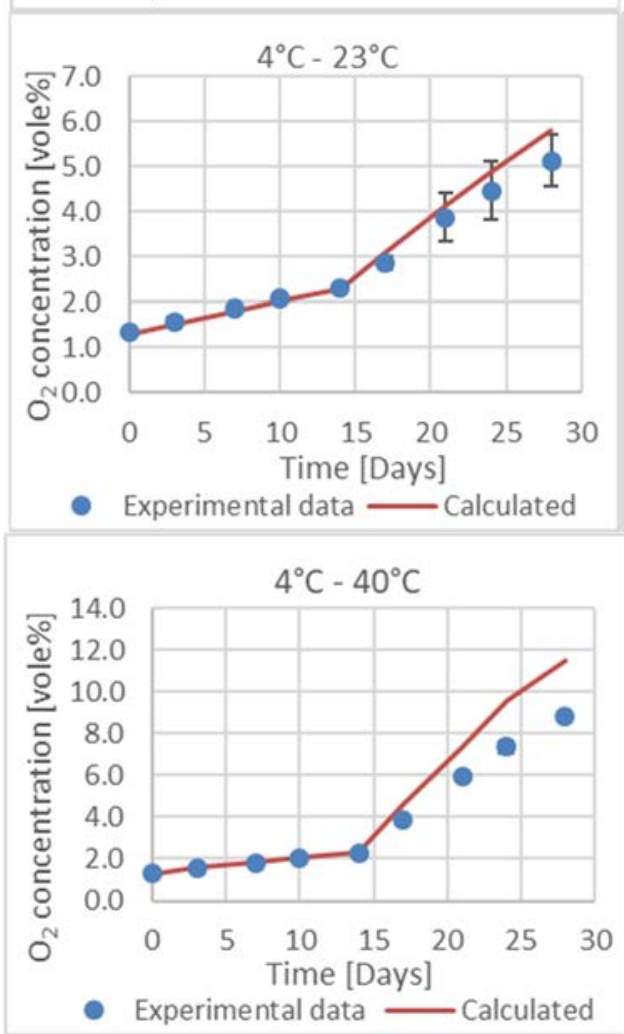

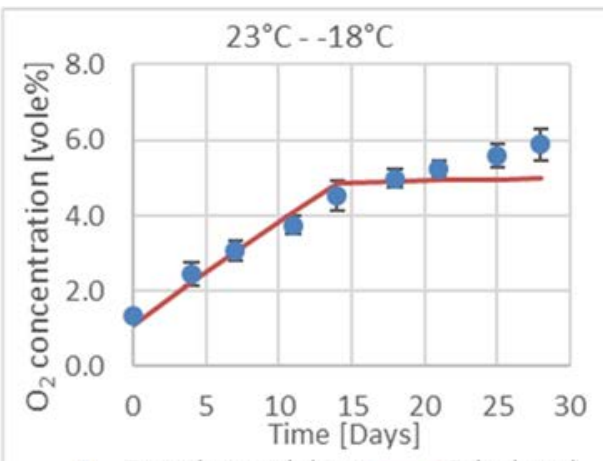

- Experimental data - Calculated

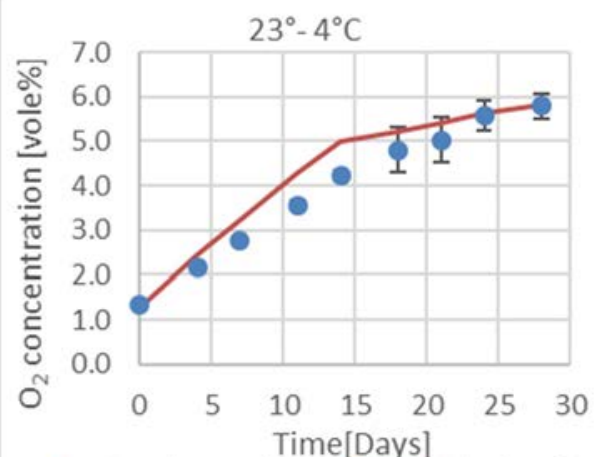

- Experimental data - Calculated

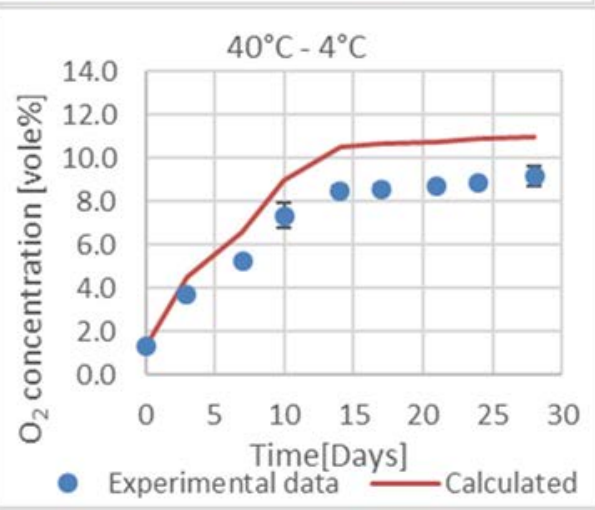

Figure 5: Oxygen concentration in polypropylene. Comparison of mathematical model and experimental results at different temperature variations.

oxygen concentration as a function of time. There is a good correlation between the model and the experimental results within the range of the standard deviations. Using literature values in the calculation gives higher deviation from the experimental data. However, the structure of the polymer materials used in the experimental work may deviate from the materials referred to in Polymer Handbook [6] due to crystallinity and density. 


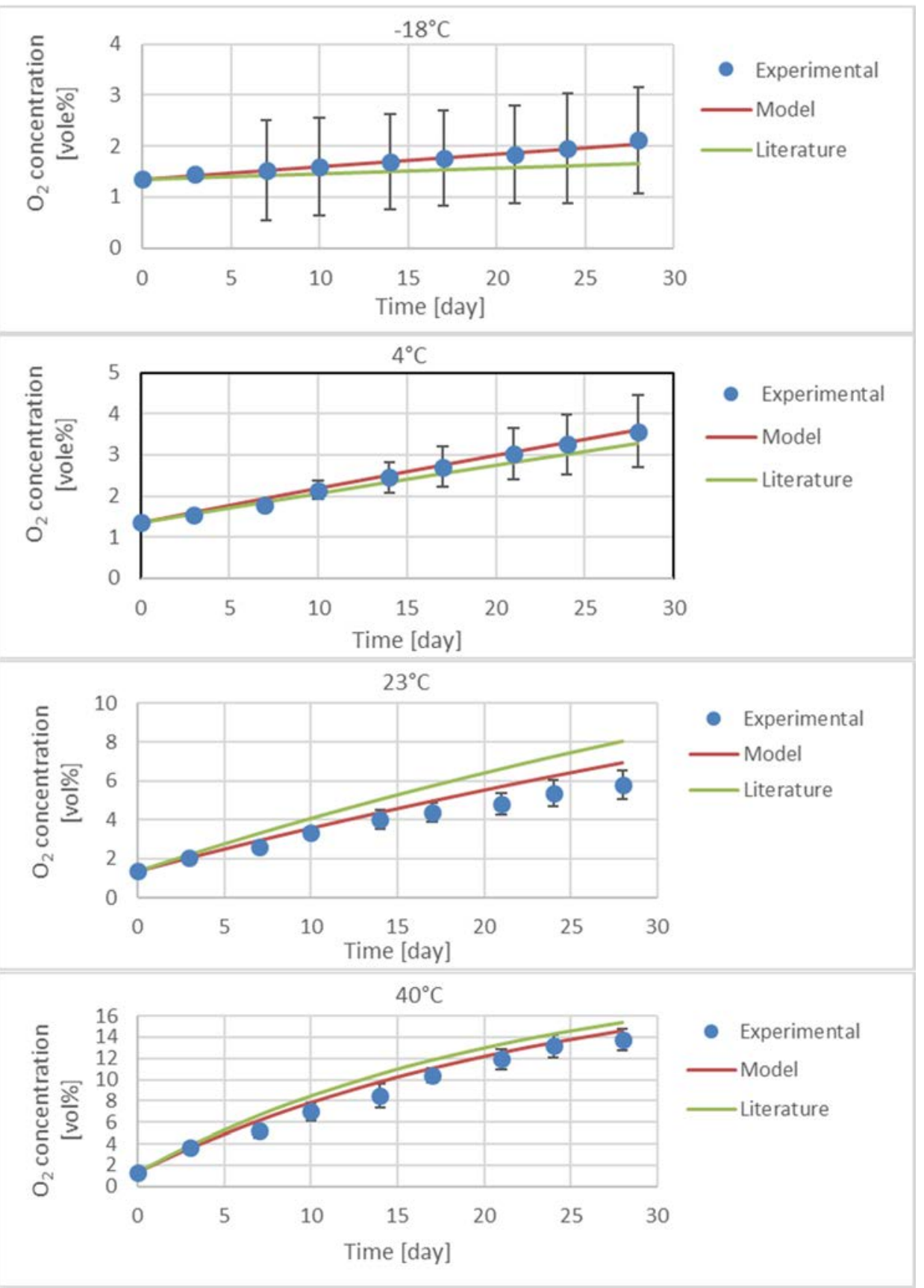

Figure 6: Comparison of mathematical model and experimental results, regarding oxygen concentration at different temperatures. 
Fig. 7 shows a comparison between the permeability coefficients in [6] and the experimental results. The permeability coefficients found in this work is lower than the literature data. This can be due to differences in density and crystallinity of the polymers. The polypropylene used in this study is a random copolymer with some percentage of ethylene. The crystallinity and the glass transition temperature are not given for the material. The glass transition temperature for random polypropylene copolymer is stated to be $-20^{\circ} \mathrm{C}$, while a homopolymer has a glass transition temperature of $-10^{\circ} \mathrm{C}$ [7]. However, a higher degree of crystallinity in the polymer will reduce the permeability coefficient. Eqn (2) is used to calculate the permeability coefficient from the experimental results. The date from the literature is valuable for the temperature range $20-70^{\circ} \mathrm{C}$. The values for the lower temperatures are estimated from eqn (3).

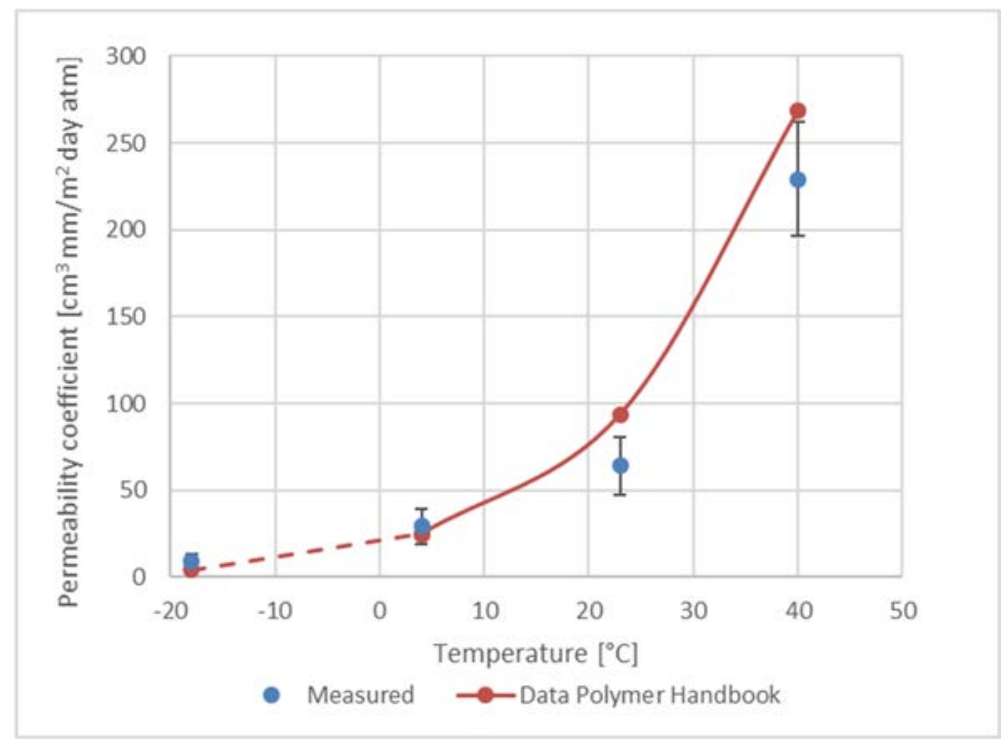

Figure 7: Comparison of permeability coefficients from Polymer Handbook [6] and permeability coefficients obtained from experimental data.

\section{CONCLUSION}

In this article the influence of temperature variations on the oxygen diffusion through a polymer material, e.g. polypropylene, is studied. The experiments are performed by measuring the concentration of oxygen in polypropylene boxes under constant temperatures and with temperature variations over time. The laboratory experiments show that the oxygen diffusion increases with increasing temperature. Changing the temperature will change the permeability rate of oxygen through the polymer. An effect of changing the temperature is that the permeation rate in the polymer becomes higher when the polymer has first been exposed to a higher temperature. This is observed when the temperature is decreased from $23^{\circ} \mathrm{C}$ to $-18^{\circ} \mathrm{C}$. A mathematical model is used to estimate the oxygen concentration in the boxes. The comparison between the mathematical model and the experimental results states that although there is a deviation between the two, the tendency of increase in oxygen concentration with time is the same. The experimental permeation rate is lower than the literature values. This may be due to differences in density and crystallinity of the polymer. 


\section{ACKNOWLEDGEMENTS}

We would like to thank Norner AS for facilitation for the experimental work. Special thanks to Irene Helland, Abdoljavad Nadimi, Sveinung Aasetre and Lene Wendelborg.

\section{REFERENCES}

[1] Kilcast, D. \& Subramaniam P., Food and Beverage Stability and Shelf Life, Elsevier Science and Technology, pp. 132-133, 2010.

[2] Norner, A.S., Packaging testing and solutions. www.norner.no/consumables/packagingtesting-and-solutions. Accessed on: 28 Apr. 2020.

[3] Siracusa, V., Food packaging permeability behaviour: A report. International Journal of Polymer Science, 2012, 302029, 2012. https://doi.org/10.1155/2012/302029.

[4] Ramos, M., Valdés, A., Mellinas, A.C. \& Garrigós, M.C., New trends in beverage packaging systems: A review. Beverages, 1(4), pp. 248-272, 2015. https://doi.org/10.3390/beverages 1040248 .

[5] Mulder, M., Basic Principles of Membrane Technology, 2nd ed., Kluwer Academic, 2003.

[6] Brandrup, J., Immergut, E.H. \& Grulke, E.A., Polymer Handbook, 4th ed., Wiley: New York, 1999.

[7] Ommexus, Glass transition temperature. https://omnexus.specialchem.com/polymerproperties/properties/glass-transition-temperature\#PM-PP. Accessed on: 11 Mar. 2020.

[8] McKeen, L., Film Properties of Plastics and Elastomers, 4th ed., Elsevier, 2017. 